\title{
The oral tradition in special care issues
}

$\mathbf{0}$ $\mathrm{n}$ January 21 st of this year, in connection with the celebration of the birthday of Martin Luther King, Jr., I had the distinct pleasure of hearing the late Alex Haley, author of "Roots", describe some of the forces which shaped his formative years. He spoke simply and eloquently about the significance of the oral tradition. Parenthetically, there was eloquence in the gestures of the translator for the deaf accompanying the speaker. Mr. Haley's thesis was that the spoken word, carried down through the generations, was indeed history and was a force which in itself generated history. In his accounting of his boyhood memories, the speakers assumed as much importance as the message. Both subject and speaker, and even the setting, were things which were imprinted on the mind of the young listener.

The presentation by Mr. Haley was dynamic and inspirational. He believed in what he spoke.

It strikes me that we need to pay more attention to the importance of the oral tradition. Those of us who teach have the opportunity to pass on our experiences to our students and to our audiences in courses and seminars, to share with them our experiences complete with failures as well as successes. We need to attach more than just scientific rationale to explain why we do the things we do. This is more than what is implied by the usual case presentations.

We have all attended presentations in which the speaker has described in great detail, with over-voluminous documentation, the success of a particular technique. We went specifically to hear of the technique, so we got what we wanted. Later, another technique which is superior comes along, and the first is forgotten. But at other times we heard of a technique used which had special benefits for the particular patient involved. This technique, too, may be abandoned, but the good it did the patient is remembered.

I have a letter which I value. It is from a hygienist who attended a continuing education course I had arranged. She said that, because of the inclusion of patients with disabilities in the course and presentations by caring dentists, physicians, and parents, she felt educated instead of being simply supplied with facts. She had not been impressed with the specifics of pharmacology or the techniques described, useful as they may have been, as much as with the obviously caring bond exhibited between the patients and the doctors. This bond helped promote the provision of care regardless of the technique being used. I like to tell people of this letter because it speaks of values. We need to talk more about such values.

Recently, at the fourth National Meeting on Special Care Issues in Dentistry, I had lunch with Drs. Bob Runzo, Norm Levine, and Manny Album, all past presidents of the Academy of Dentistry for the Handicapped. We reminisced about past times and carried on the oral tradition, although not consciously aware we were doing so. The little vignettes we talked of were things that had influenced us, and perhaps others, and served as a reminder of why we were there. At the conclusion, Dr. Runzo remarked that we should be doing more of this. He was right.

\section{Henry L. Kanar, DDS, MS}

Associate Professor of Dentistry

Department of Orthodontics and Pediatric Dentistry

The University of Michigan, Ann Arbor 